Since the production of the first Golden Cross sweet corn by Glen Smith, hybrid sweet corn production has greatly progressed, with the adaptation of special inbreds and their hybrids for particular areas of the States. In view of the fact that sweet corn is primarily a canners' crop, great stress has been laid on uniformly maturing hybrids, and sweet corn breeders have established a complete series of early, medium and late inbreds and single cross $(A \times B)$ hybrids, so that growers can use mechanical pickers and sweet corn canneries can work over a spread of time. Compared with field corn, sweet corn breeding has been to some extent simplified because single crosses may be used, the prices of seed being higher than for field corn. With the maturity range established, attention is now largely focused on quality testing. This is an elusive item to estimate, and although the sugar content of kernels is of some value, still the only satisfactory method is by tasting, usually in the raw state, rather than by any laboratory tests, such as estimating translucency, or puncture testing for pericarp tenderness. By experience, sweet corn breeders generally agree upon what good-quality sweet corn should taste like. Attention is also paid to the behaviour of the different sweet corn hybrids under freezing methods, since more ears are sent to market on ice each year.

Many of the northerly experiment stations in the United States and also in Canada are selecting early, hardy sweet corn lines. Owing to the sudden killing frosts towards the end of the season, these strains must be so adapted that seed is sufficiently matured for safe picking and for artificially drying before being otherwise killed on the ear. There have been various determinations of the optimum drying conditions. In general a temperature of $100^{\circ} \mathrm{F}$. for three days is often sufficient to bring down the moisture content of the seed in the hard dough stage to a level permitting safe storage. Besides pushing sweet corn production northwards there is also an active attempt to spread sweet corn for canning and direct eating into the Southern States, where white, dent corn is now grown for roasting. The resistance to the use of yellow sweet corn seems largely to be based on ignorance of the southern farmers and to the fact that no hybrid strains have been adapted to their climatic conditions, many northern hybrids being unable to meet the severe attacks of the corn ear worm in this region. These particular problems are now being overcome.

For a long time much attention has been paid to the history of the corn plant, concerning the origin of present forms and how it spread through the North American continent with the movements of the early American Indians. In addition, corn is one of the few cultivated plants the prototype of which has so far not been discovered growing wild in Nature, and its ear, so different from the female inflorescence of other members of the Gramineæ, offers interesting material for investigation. There is a division of opinions as to the source of corn. Mangelsdorf, Reeves and Merrill believe corn is a specialized product of selection by early American Indians of a grass that grew wild on the American continent. The present site of this prototype is still to be located, but evidence points to South America as the primary centre of origin. Teosinte (Euchloena) is a hybrid between maize and Tripsacum, and is not a progenitor of maize, although where teosinte grows as a weed in Mexican corn fields there is a high incidence of hybridization. On the other hand, Edgar Anderson suggests that besides genetical indications, there are several pieces of ethnological evidence which suggest Burma as a possible source for the origin of corn. He has enumerated several pieces of circumstantial evidence showing similarities between Asiatic and Pre-Conquest civilizations. In addition, it is known that other members of the Tribe Maydeæ, to which maize belongs, occur in tropical Asia.

Similarly, views on the origin of sweet corn are at variance, Mangelsdorf believing that the $s u$ mutation for sugary kernels has occurred spontaneously in different areas throughout America, and has been adopted by local farmers in those areas for specialized use, such as making fermented liquors; while Edgar Anderson conceives that the sugary mutation has gradually spread northwards across the American continent from a more southerly point of origin. At the present time, although much light has been shed on these problems, the origin of corn still awaits a final solution.

Acknowledgments are made to the Agricultural Research Council of Great Britain for funds allowing the writer to visit the corn belt of the Mid.Western States.

\section{ASPECTS OF THE LOCOMOTION OF WHALES}

By R. W. L. GAWN, O.B.E.

Superintendent, Admiralty Experiment Works, Haslar

$\mathrm{R}^{\mathrm{T}}$ EPORTS of the 1946-47 British Scientific Expedition to the Antarctic Whaling Ground have revived interest in the locomotion of whales and other marine mammals and fish. Some interesting studies and information on this subject already exist, but many of the reports of speed recorded in the past have proved rather conflicting in character. Care appears to have been taken on the recent Expedition to obtain reliable observations, and it now appears to be substantially confirmed that a blue whale can attain a speed of 20 knots for a short burst of about ten minutes duration, and maintain a speed of $14 \frac{1}{2}$ knots for two hours and probably longer. A killer whale may obtain slightly higher speeds.

The shape of fish and marine mammals has naturally been an inspiration for the forms of underwater bodies for a great many years, and investigations have been carried out accordingly. It is pertinent to examine whether any lessons can be learnt from the whale and other marine creatures that can contribute to faster speeds of submarines and other underwater locomotive bodies.

Particulars of the shape of fish and marine mammals were given so long ago as $1919^{1}$. The form is not unlike that of a good streamline body. A blue whale of normal proportions may be about $90 \mathrm{ft}$. long and as much as 120 tons weight. The shape is illustrated in Fig. 1.

In order to propel a smooth rigid body of this size and shape at $20 \mathrm{knots}$, it is estimated that 520 horse. power would have to be developed by the whale. The estimate for other speeds is shown in the curve in Fig. 4.. This curve is deduced from measurement of the resistance of models of smooth rigid bodies towed in water. These bodies form eddies which account for a fair proportion of the total power. It may be argued that the whale may succeed in avoiding eddy resistance by the natural flexure of the tail and 


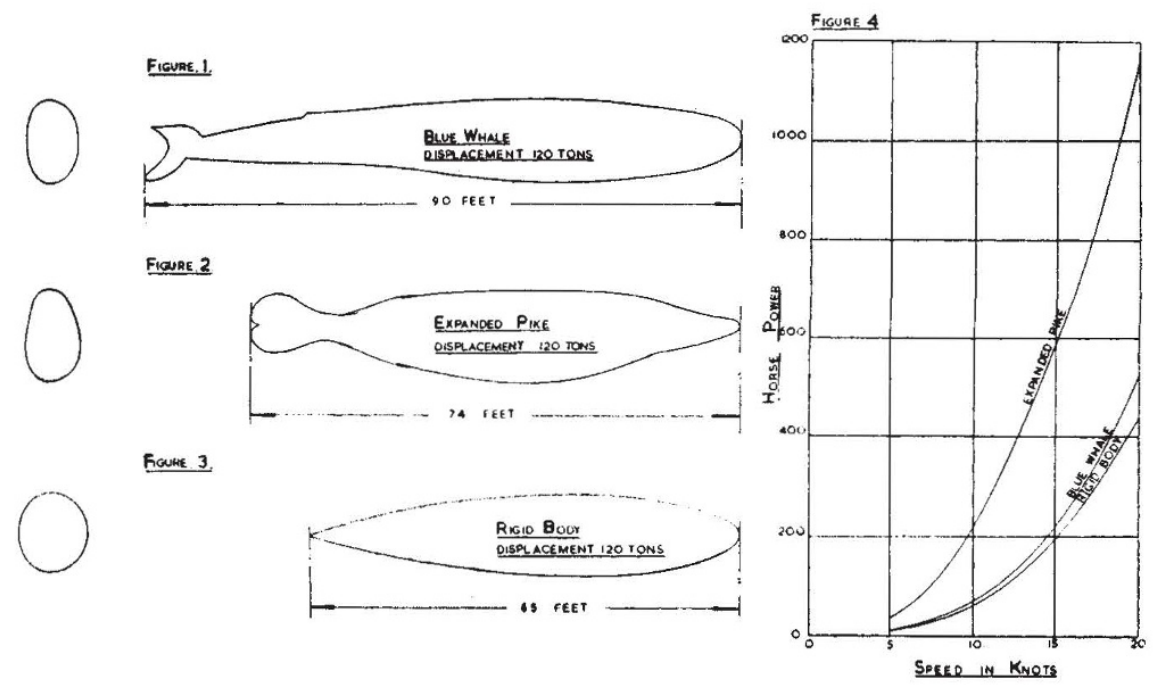

develop 9 .horse-power per ton of total weight. Thus the estimate of horsepower given in the curve is not inconsistent with the power obtainable from the muscles of the mam. mal.

It may be suggested that the surface friction resistance of the whale is less than that for turbulent flow past a rigid body. Taking a favour. able view, the flow may be laminar. The horsepower would then be much less than that given in Fig. 4. While there is no definite evidence to prove or disprove this, such an explanation of the speed of the whale

after-body generally. On the other hand, the unevenness caused by the fins and the fluting of the body will result in some increase of the horse-power required as compared with a smooth rigid body. It is also assumed that the propulsive efficiency of the tail of the mammal is equal to that of the best marine propeller, namely, 75 per cent. Here again it may be argued that a higher efficiency should be assigned because the tail of the whale is a com. paratively large surface and moves at a slow rate. It may therefore be assumed that the rate of change of momentum to propel the whale is achieved by discharging a large quantity of water astern at a comparatively low speed. As a result the kinetic energy wasted in the race will be reduced. The energy so lost may be only about 10 per cent of the total, which indicates a possible 90 per cent for the efficiency. In assessing an efficiency of 75 per cent, I have, however, been guided by the results of a few experiments on flapping fins that have been carried out abroad.

It is of interest that the horse-power curve so obtained is very similar to that previously recorded in Nature by Prof. A. Krogh ${ }^{2}$, although the method of estimate is different. In particular, the previous estimate assumed an efficiency of 100 per cent for the 'propeller', which is clearly inadmissible because of the loss due to kinetic energy in the water discharged sternwards.

If the curve in Fig. 4 truly represents the performance of the live whale, the developed horse-power per ton is 4.35 at 20 knots and 1.75 at 15 knots. This expenditure of power in relation to the weight is comparatively large and implies that the whale attains its remarkable speed by exertion of large power rather than by any special virtue in shape of body or smoothness of skin. There is no known measurement of the power which a whale can develop. Some approach to the problem can, however, be obtained from physiological researches. This question has been discussed by Gray $^{3}$ and Barcroft ${ }^{4}$. It appears that 0.01 horse-power per $\mathrm{lb}$. of muscle is developed by athletes and dogs. There seems no reason for believing that whale muscle is more efficient as a machine than the muscle of other mammals. It also seems established that about 40 per cent of the weight of a whale consists of muscle. On these assumptions it would appear that the whale can is unnecessary, since the horse-power mentioned above is not beyond that to be expected from a creature of 120 tons weight. There is also independent evidence $^{1}$ that great power is, in fact, developed by the whale; for example, a Sei whale is reported to have towed a vessel at 12 miles per hour, and a blue whale to have towed a steamer at 7 miles per hour, although the engines were working full speed astern.

A point which must not be overlooked and on which further information would be valuable is the means by which the whale avoids excessive rise of temperature when developing this large power. Assuming 22 per cent efficiency for the muscular engine, then the rise of temperature of the whale for a 10-minute burst of speed at $20 \mathrm{knots}$ may be about $3^{\circ} \mathrm{F}$., unless arrangements are made for dissipating the heat.

It should be added that the estimate of horse. power in Fig. 4 assumes that the whale is so deeply submerged that surface waves are not produced. It is understood that a whale normally proceeds at about three fathoms submersion and frequently on the surface. If the whale is proceeding on the surface at low buoyancy, it is estimated that the horse-power at the top speed would be treble that in the figure. If at three fathoms depth, the increase would be about 50 per cent. These estimates are deduced from experiments that have been made in water on models of shapes analogous to the whale.

A fish for which there is reliable information is the pike ${ }^{5}$. Experiments were carried out in the Hamburg Ship Model Experiment Tank. An anæsthetized pike was towed in the experiment tank, and the resistance measured at various speeds. The resistance was much greater than for a smooth solid body of similar shape. The oil exuded by the. fish mollified the unevenness of the skin due to the scales to some extent, but the reduction in skin friction was inconsiderable. Observations of the speed of pike gave maxima of 6-8 knots, the mean speed being 5 knots. The effective horse-power per ton is considerable and varies from 26 at 8 knots for a large pike to 53 at. $6 \cdot 8$ knots for a small pike. The tests established that the speed and form of individual fishes of the same type vary considerably. So far as they go, the experiments do. not support the theory that fish have abnormally low surface friction.

Possibly anglers whose equipment has suffered in the struggle with a lively victim might hold the view 
that the pike tested in the Hamburg Tank were rather unenterprising. I am not an angler, but I have observed fish and have been impressed with their capacity for developing high acceleration over short periods. This led me to take the opportunity when in Hamburg before the War to discuss the experiments on pike with Prof. G. Kempf, director of the Hamburg Experiment Tank. I feel assured that the investigations on the pike were most care. fully conducted, and that the results should be accepted as an accurate record of the performance of the species tested. Very complete particulars were taken of the shape of the pike. Fig. 3 indicates a pike of weight $9.05 \mathrm{lb}$. expanded to 120 tons to compare with the blue whale shown in Fig. 2. The horse-power for the pike as measured in the Hamburg Tank has also been expanded by the usual method adopted in ship-model experiments to compare with a whale. It has again been assumed that the pro. peller efficiency is 75 per cent. The horse-power curve for the expanded pike is shown in Fig. 4. The horse-power considerably exceeds that for the whale. This naturally casts a doubt on the estimate for the whale, but it may also reflect the wide difference between a small freshwater fish and a large deep-sea mammal. It is of interest to compare the performance with that of a rigid body of good design. Such a body is shown in Fig. 3. A model of this body has been tested both in water at the Admiralty Experiment Works, Haslar, and also in a wind tunnel. The horsepower curve deduced from the results is also shown in Fig. 4. The results compare favourably with the expanded pike and the whale.

Porpoises have been credited with a speed of 25 knots. This is a very high speed for a small creature to maintain for any length of time. Proceeding in the same way as for the whale, it is estimated that 14 horse-power would be required at this speed for a porpoise of 0.16 ton weight. This represents the high figure of 87 horse-power per ton. If, how. ever, the speed is $20 \mathrm{knots}$, the horse-power per ton is reduced to 43 , which is comparable with the pike.

It would be of great interest to ship designers and more particularly those associated with the design of submarines and other underwater bodies to obtain some reliable information concerning the whale. The day may be far distant when the towing power developed by the muscles of the whale can be accurately measured, but it would be of considerable interest to have the views of physiologists as to the muscular power. It should not prove a difficult matter to obtain a reasonably accurate measurement of the towing resistance of whales at various speeds. This is recommended for consideration by those responsible for organising future whaling expeditions. The whale differs from other marine creatures in that the tail is horizontal and moves vertically. Some information on the size of the tail and fins, and the method by which the whale dives and surfaces and maintains stability for course and depth, would also be of interest. If the particulars of the fin surfaces could be obtained, there is scope for wind tunnel investigations on the whale similar to the interesting tests on fish stability carried out by Harris ${ }^{6}$.

I wish to express my appreciation of the help generously given by Dr. R. A. M. Case, of the Royal Naval Physiological Laboratory. Dr. Case was the leader of the 1946-47 British Scientific Expedition to the Antarctic Whaling Grounds, and he has provided particulars of the size and speed of the blue whale and has very kindly given references to the physiological work quoted in this article.

\author{
2 "Experiments in a Wind Channel on Elongated Bodies of Approx- \\ imately Streamline Form". $R$ and $M$ 607, March 1919 (Advisory \\ Committee for Aeronautics). \\ - Krogh, A., Nature, 133, 635 (1934). \\ Gray, J., J. Exp. Biol., 10 (1933). \\ "Barcroft, J., "Features in the Architecture of Physiological Function" \\ (Camb. Üniv. Press, 1938). \\ ' $Z$. Ver. Deut. Ing., 79, No. 33. \\ - Harris, J. E., "The Role of the Fins in the Equilibrium of the \\ Swimming Fish. I. Wind Tunnel Tests on a Model of Mustelus \\ canis (Mitchell)", J. Exp. Biol. (1938). II. "The Role of the \\ Pelvic Fins", J. 'Exp. Biol. (1936).
}

\section{OBITUARIES}

\section{Dr. C. C. Hurst}

Charles Chamberlain Hurst, whose death occurred on December 17, was born in 1870 and educated at Wesley College, Sheffield. As a member of the family firm at Burbage, near Leicester, he was early brought into contact with horticultural practice and problems, and at the same time afforded opportunity for embarking on the investigations with which his name is connected.

Hurst was working at cross-fertilization in orchids when Bateson's papers in the Journal of the Royal Horticultural Society in 1900 brought the news of Mendel's discovery to the English-speaking world. Hurst at once got into touch with Bateson and started experiments with rabbits and poultry with the view of testing Mendel's conclusions. With rabbits he was able to confirm the results of Cuénot on coat colour in mice, and his extensive series of crosses among poultry, an account of which appeared in the Reports to the Evolution Committee of the Royal Society in 1904, added considerably to our knowledge of the genetics of the fowl. Better known was his demonstration of the recessive nature of chestnut in horses, which provoked much discussion when read before the Royal Society.

Perhaps the piece of work for which Hurst is most likely to be remembered is his paper on the "Inheritance of Eye-colour in Man". Through the careful and laborious collection of data from his native village of Burbage, where he was well known and trusted, he was able to determine the recessive nature of blue to non-blue eyes, and must thereby receive the credit for being the first to demonstrate the Mendelian inheritance of a 'normal' character in man.

Although he had, as it were, strayed for a time in the animal kingdom, he had by no means given up his horticultural interests. His attraction to the genus Rosa led him to form an outstanding collection of wild forms from all over the world, and his hybridiza. tion work contributed much to the understanding of this remarkable case of polyploidy.

As to many another scientific worker, the outbreak of war in 1914 came as a sad misfortune. In his capacity of a Territorial officer he joined the Army, and at the conclusion of hostilities he found himself unable to carry on at Burbage. Thereupon he entered Trinity College, Cambridge, as a fellowcommoner, and eventually his research work led to the award of the Sc.D. degree by the University. Fortunately he had been able to shift much of his collection of rose species to the Botanic Garden at Cambridge and was able to carry on his study of the genus, cytologically as well as in the field. Meanwhile he wrote his book on "Creative Evolution", an 